\title{
Psychiatrists and psychologists: can they work together?*
}

In 1984 a joint British Psychological Society/Royal College of Psychiatry conference was held at the College's Autumn meeting. The theme was 'Psychiatrists and Psychologists-Cooperation and Confrontation'. It was reported in the Bulletin of the College (June 1985) and in Clinical Psychology Forum.

More controversial issues were pursued at a follow-up meeting in October 1986: 'Psychiatrists and Psychologists - Working Together for Planning Services in the Post-Griffiths Era' which was also reported in the Bulletin and the Forum (October 1987). In the afternoon participants split into five speciality groups. The group concerned with the elderly decided to develop their collaboration by setting up a joint PSIGE-SPOA working party.

This working party organised a meeting on 26 November 1987 at the King's Fund Centre which was attended by 40 psychiatrists and 40 psychologists who work with elderly people. In the morning speakers from the two professions presented short papers on:

the development of psychiatric and psychology services for elderly people and how they relate to each other

(Alan Tatham \& John Wattis)

planning mental health services for the elderly

(Colin Godber \& Charles Twining)

research trends in the care of the elderly

(Anthony Mann \& Bob Woods)

manpower and training for developing a mental health service for the elderly

(Garry Blessed \& Elspeth Stirling)

These presentations gave background information and a stimulus to discussion by the afternoon's four working groups - on working, planning, researching and evolving together.

\section{The present position: psychology}

The number of clinical psychologists working with elderly people is relatively small, and many posts are

*Report of a meeting of the Psychologists' Special Interest Group in the Elderly (PSIGE) and the Section for the Psychiatry of Old Age (SPOA) at the King's Fund Centre on 26 November 1987.

This report was prepared by a joint working party of PSIGE and the SPOA: Andrew Norris, Brice Pitt, Sally Robbins, Alan Tatham and John Wattis. It was edited by Brice Pitt. unfilled. Recruitment is a problem, but not only to work with the elderly: there is a dearth of clinical psychology training places. Recruitment is enhanced where it is the district's policy to develop a psychology service for elderly people rather than single posts. Such services contribute to all aspects of work with elderly people, including psychogeriatrics, geriatric medicine, social services, the voluntary sector and health promotion, in hospital and other institutional settings and in the community. Not only do the psychologists have a clinical commitment to assessment and therapy, but they also become involved in other areas such as teaching, planning and research. Concepts and approaches from other speciality areas such as neuropsychology, systems work, organisational psychology, applied science, evaluation and experimental design, family therapy and work with carers, loss and bereavement, mental handicap, behavioural approaches and normalisation need to be accommodated.

There is a commitment to teamwork and a willingness to address interdisciplinary issues. However, clinical psychologists working with elderly people are finding that the demands of their role outstrip manpower.

\section{Psychiatry of old age}

In 1981 there were an estimated 120 consultants in psychiatry of old age. By 1987 this had more than doubled. A recognisable pattern of work has evolved, with a multidisciplinary and community orientation. Four-fifths of consultants in the field offer a comprehensive age related district service and only $10 \%$ a service for dementia sufferers alone. This reflects the increasing realisation that old people with other psychiatric disorders than dementia also have special problems, about which knowledge is growing. It also reflects the need for close cooperation with geriatric medicine, psychology and social services, as complicated psychiatric/psychological/ medical/social problems are so frequent. About half the consultants in the field in 1987 worked full-time in old age psychiatry and the remainder worked five or more sessions. There were major regional variations in provision, but those indicators available suggest that specialised services are preferable to provision for old people by non-specialist general consultant psychiatrists. 


\section{Summary of Working Group on 'Working Together'}

A consideration of the developing pattern of psychological and psychiatric services for the elderly and how they relate to each other

Chair: John Wattis

Secretary: Alan Tatham

The main points discussed were:

\section{Special skills}

Obvious different skills include the prescription of drugs by the psychiatrist and the administration of certain psychometric assessments by clinical psychologists. Differences arise from different professional backgrounds, and different basic training emphases, on abnormal (medical) and normal (psychological) human attributes and behaviour. The psychogeriatrician tends to be concerned with the patient, while paying attention to the context in which that person functions, whereas the clinical psychologist will tend to focus on the environmental, social and organisational systems in order to assist the individual.

\section{Principles}

The professions agree in their commitment to elderly people, and to enabling them to attain the highest possible quality of life.

The professions are interdependent, because of the many factors which cause the elderly to come to their services.

Both recognise that the elderly are people, with basic human rights and dignity, as well as special needs. Human rights-e.g. to independence and privacy - must be sensitively balanced against undue risks-e.g. of serious self-neglect, exploitation or harm to others.

Carers also have rights and needs.

\section{Problems}

There is no clear definition of a 'team'.

To whom should referrals be made - the doctor, the psychologist, the community psychiatric nurse, the social worker, or whoever is the team leader?

Any team needs a coordinator: who should take this responsibility?

Personal skills and local knowledge may warrant leadership despite a lack of formal training skills or qualifications.

It is difficult to work in a team led by someone less experienced that oneself.

The professions lack equity of management structure. Unlike their consultant colleagues, clinical psychologists feel part of line management. Yet psychogeriatricians may envy the freedom of clinical psychologists within their job descriptions.
Both professions spend relatively little time with "hands on", yet they adopt or are given a high profile within the team.

Nevertheless they are the only professions who preserve client contact despite seniority. They are often alone on planning committees and teams in still seeing those for whom they are planning.

\section{Shared approaches and objectives}

to address all issues concerned with the full range of psychiatric disorders in older age to raise the status of work with elderly people to promote health, educate others and influence systems to consult and learn from carers to appreciate that, because of different training and orientation, the professions' perceptions may be different and yet valid: they can learn from each other.

\section{Summary of Working Group on 'Planning Together'}

Issues in planning mental health services for elderly people

Chair: Roy Simons

Secretary: Sally Robbins

There are difficulties in:

recruitment (partly due to lack of glamour in the work and lack of effective community pressure) uncertainty over the Griffiths Report on Community Care and its implementation providing 'round the clock' care for the most disabled clients.

A four-stage plan might entail:

looking at the present situation

agreeing aims to give planning continuity considering the implications of achieving those aims, especially where they might mean increasing demands on the service measuring success.

The rise in population in those aged over 85 is a helpful statistic to quote when making plans.

Progress in planning is facilitated by: relative predictability of need clear planning structures explicit communications sharing of aims.

Five recommendations emerged from discussion of the aims of planning: aims should be locally directed, discussed and agreed

are best expressed as discrete projects which relate clearly to each other and the overall service plan, and can be given appropriate priority for funding should be realistic 
should be client-centred

can be shaped by experiences in other developing services, e.g. the mentally handicapped.

Successful planning requires proactive strategies making intelligent use of background research and local data. Possible strategies emerging from discussion included:

devote regular time and effort to planning issues use Joint Finance intelligently to provide funding and good PR

'store' small, fully worked up projects so as to capitalise on unexpected funding opportunities blend opportunism with strategic planning.

\section{Summary of Working Group on 'Researching Together'}

Research trends in the care of the elderly

Chair: Linda Henneman

Secretary: Brice Pitt

Psychogeriatric research is in a state of healthy adolescence, even though time and funding are limited. Psychiatrists and psychologists are more likely than other members of the multi-disciplinary team to have research experience and therefore to undertake research, individually or in collaboration with each other.

The construction and refining of screening instruments, sharpening research diagnostic criteria and other epidemiological developments, and such technological advances as imaging and computerised cognitive assessment, have proved especially fruitful. Other promising areas include:

stresses on families

stresses on staff, staff morale

the effectiveness of behavioural modification techniques

neurosis, especially the housebound elderly

evaluation of psychogeriatric services, e.g. intensive community care of demented people collaboration in early diagnosis, e.g. memory clinics, and in assessment of neurotropics and memory training techniques.

Research can be stimulating, exhilarating, rewarding and a boost to staff morale. It can also be frustrating and demanding. Problems include: difficulties in obtaining research grants problems of obtaining satisfactory informed consent from subjects who are confused or very despondent

difficulty in applying truly experimental methods to many psychogeriatric problems (and the difficulty in finding suitable controls)

isolation and remoteness from academic establishments

the risk of failure

too many clinical commitments possible reluctance by managers to allow clinicians research time, or a bias towards research with immediate practical applications rather than that which extends knowledge

political pressures may outweigh research findings in determining developments, e.g. whatever the consequences of closing a mental hospital for its patients are found to be, it will never be reopened. Psychologists and psychiatrists need to collaborate in research as in other ways. They çan support, stimulate and complement each other. Psychiatrists might well look to psychologists for their more reliable expertise in research methodology, psychometry and the analysis of behaviour, while the psychologists may benefit from the psychiatrists' wide access to patients, medical knowledge and executive powers. A bonus from a well developed psychogeriatric research programme is that psychologists who get involved during their training may well choose that field when they are trained.

\section{Summary of Working Group on 'Evolving Together'}

Developing a mental health service for the elderlymanpower and training

Chair: Carole Trotter

Secretary: Andrew Norris

\section{Recruitment, training and manpower}

The contribution which each profession can make to the care of the elderly has been widely recognised in recent years, and is reflected in the huge increase in posts established in the speciality - one of the few current areas of development within the health service. Unfortunately it is not always possible to fill these posts. Reasons for this were explored by the group and a number of suggestions to remedy the situation were made.

\section{For psychiatry:}

Each health district should have a minimum of one whole time equivalent consultant psychogeriatrician post, and eventually there should be one w.t.e. consultant per 20,000 population aged over 65 in the catchment area.

Medical students should be taught more old age psychiatry.

A four-month pre-registration placement should be available in old age psychiatry.

All junior rotation schemes should have a placement in old age psychiatry, which might include a joint placement in geriatric medicine.

There should be more senior registrar posts in old age psychiatry, which should be Regionally funded. 
For clinical psychology:

Each district should establish a minimum one w.t.e. Principal Grade psychologist specialising in the care of the elderly.

There should be one w.t.e. such post for every 20,000 population aged over 65 in the catchment area.

There should be more funded training posts in clinical psychology.

Work with the elderly should be included as a core placement as part of the British Psychological Society course accreditation requirements.

An increase in the number of supervisors for work with the elderly needs to be encouraged.

Diploma requirements should include more assessments in relation to the elderly.

Academic input concerned with psychology and the elderly on clinical psychology training courses should be standardised.
Opportunities for 'updating' on developments in the field need to be created.

Joint/rotational basic grade posts to include the elderly should be encouraged.

Senior grade psychologists might be encouraged to supervise more than one specialty.

Posts of all grades should be available within each health district.

\section{Conclusion}

It is now well established that both psychiatry and clinical psychology have much to contribute in the field of old age. It is therefore important to ensure that the quality and quantity of this contribution are well known, and that every effort is made to attract people to the speciality.

\section{The work of the Overseas Desk}

\section{Background}

The Overseas Desk of the College was set up in March 1988, following discussion of the need for such a development at the Executive and Finance Committee in May 1987, and a description of what it might do was published in the Bulletin on February 1988. Since its inception the Working Group for Overseas Liaison has met regularly. Membership of this Working Group has been the Dean; Dr Fiona Caldicott, Sub-Dean; Miss Lynette Napper, Education Officer; and Miss Suzanna Goodwyn, Assistant Education Officer. This Working Group is answerable to the Executive and Finance Committee of the College, and its minutes go to the Education Committee; it is an integral part of the Education Department in the College.

\section{Remit of the Overseas Desk}

The Working Group for Overseas Liaison has concerned itself with the four main areas for which the Overseas Desk was established. These have been as follows: (i) Overseas trainees Over the last few months the Overseas Doctors' Training Scheme of the Royal College of Psychiatrists has been established.

(ii) Mutual recognition of psychiatric qualifications Consideration has been given to qualifications in Europe, in other Englishspeaking countries, and in other countries.

(iii) Links with, and services for, members overseas There is scope for considerable development. So far this item has been implemented by setting up Regional Meetings of the College.

(iv) Psychiatric training overseas Members of the College resident in the British Isles have continued to make visits to countries overseas, especially those with traditional links with the Royal College. These visits have involved teaching, examining for local postgraduate examinations, and improving psychiatric educational facilities. The College has been asked to provide examiners in Singapore and Sri Lanka and has recently carried out an Approval visit to Hong Kong. 